\title{
FGFR2 Fusion Positive
}

National Cancer Institute

\section{Source}

National Cancer Institute. FGFR2 Fusion Positive. NCI Thesaurus. Code C150616.

An indication that expression of a fusion containing sequences from FGFR2 has been detected in a sample. 